entropy

ISSN 1099-4300

www.mdpi.org/entropy/

\title{
Editorial
}

\section{Papers from the Foundations of Information Science 2002 (FIS 2002)}

\author{
Pedro C. Marijuán ${ }^{1}$ and Shu-Kun Lin ${ }^{2,3}$ \\ ${ }^{1}$ Fundación CIRCE, CPS-Universidad de Zaragoza, Zaragoza 50018, Spain \\ E-mail: marijuan@posta.unizar.es \\ ${ }^{2}$ Molecules Editorial Office, Ocean University of China, Qingdao 266003, Shandong Province, China. \\ Tel. \& fax ++86 5322031522 (office), Tel. ++86532 2031860 (office direct), Tel. ++86532 590 \\ 6113 (private), E-mail: linsk@ouc.edu.cn \\ ${ }^{3}$ Molecular Diversity Preservation International (MDPI), Matthaeusstrasse 11, CH-4057 Basel, \\ Switzerland \\ E-mail: $\underline{\operatorname{lin} @ \text { mdpi.org }}$
}

Received: 12 February 2002 / Published: 15 February 2003

The following papers in the first issue of Entropy, volume 5, 2003, were presented at the electronic conference on Foundations of Information Science FIS 2002 (http://www.mdpi.net/fis2002/). The running title of this FIS e-conference was THE NATURE OF INFORMATION: CONCEPTIONS, MISCONCEPTIONS, AND PARADOXES. It was held on the Internet from 6 to 10 May 2002, and was followed by a series of discussions, structured as focused sessions, which took place also in the net from 10 May 2002 until 31 January 2003 (close to 400 messages were exchanged, see: http://fis.iguw.tuwien.ac.at/mailings/).

The FIS 2002 e-conference (http://www.mdpi.net/fis2002/) was organized by Pedro C. Marijuán and Wolfgang Hofkirchner (scientific secretariat) and by Shu-Kun Lin and Sen Lin (technical secretariat). The chairs of the conference sessions were: Koichiro Matsuno, Peter Érdi, John Collier, John Holgate, Wolfgang Hofkirchner, and Ted Goranson. The MDPI Molecular Diversity Preservation International (http://www.mdpi.net/) hosted the web pages of the conference, and the FIS Foundations of Information Science organization (http:/fis.iguw.tuwien.ac.at/) hosted the web pages of the post- 
conference discussion. Partial support of WESS (The Washington Evolutionary Systems Society) for this edition is acknowledged.

A conference report and a summary [1] will survey the main topics addressed at FIS 2002. Basically, analyzing the problems around the concept of information has been the central idea of the FIS initiative (starting out from its origins in the 1994 conference in Madrid); and highlighting the fundamental differences between information and mechanics (and the interdisciplinary scheme of reductionism) has become one of its most strategic tasks. The FIS 2002 conference report will cover:

1. The problem of information and the FIS initiative.

2. Reductionism: life versus mechanism.

3. Advancing the new information synthesis.

\section{Reference}

1. Marijuán, P. C. Conference Report: the Foundations of Information Science FIS 2002. Entropy, 2003, 5, 000.

(C) 2003 by MDPI (http://www.mdpi.org). Reproduction for noncommercial purposes permitted. 